\title{
Geographic Information System and Spatial Data Infrastructure: A Developing Societies' Perception
}

\author{
Anthony G Tumba*, Anuar Ahmad \\ Faculty of Geoinformation and Real Estate, Universiti Teknologi Malaysia, 81310 Johor Bahru, Johor, Malaysia \\ *Corresponding Author: anthonytumba13@yahoo.com
}

Copyright (C) 2014 Horizon Research Publishing All rights reserved.

\begin{abstract}
The perception of geographic information system and spatial data infrastructure in the developing societies is vague. Developing societies in the context of this paper are societies that are disadvantaged in the provision of geographic information system and spatial data infrastructure. The notion is that there is no clear cut understanding of geographic information system and spatial data infrastructure as perceived by societies who are still lagging in these technological ideas. Previous studies and web based sources on this subject matter form the basis for analysis, case study of three geospatial regions were viewed and analyzed. In this paper, different reasons for these information gaps were looked into, from the terms used in describing the two, to the models used for their implementation and the provision of facilities for implementation. The result obtained showed a lack of basic geographic information science background, failure in achieving a spatial data infrastructure standard and component system failure resulted in the perception. A model that is specific to developing societies in the opinion of this paper is what is needed. A suggested model to assist in refocusing the quest for national geographic information system and spatial data infrastructure towards people oriented spatial information services is made.
\end{abstract}

Keywords GIS, SDI, Developing Societies, Perception

\section{Introduction}

Geographic information system (GIS) can no longer said to be new in the spatial information world; it has grown tremendously over the years due to advancement in science and computer graphics technology. According to Jack Dangermond, the founder of environmental science research institute (ESRI), when Roger Tomlinson created the first GIS in the 1960s known then as Canada Geographic Information System (CGIS), it wasn't intended for design, but was meant for inventory and interpretation purposes of geographic features [17]. Today, the definition does not only cover design, inventory and interpretation, but includes the management and sharing of the derived information. The early stage of GIS saw the use of personal computers to capture, display, manipulate, analyze and store geographic information [10,2]. GIS is defined today by many authors in different ways, notwithstanding, most agree with the fact that it is a tool for capturing, displaying, analyzing, storing, retrieving and managing of geographic information. Since GIS is a tool for retrieving and management of processed geographic data, then such information is meant for reuse, either by the desktop author or by any other persons, organizations or institutions, hence infrastructures, a channel for delivering the reuse of these services must be provided $[4,16]$.

The term spatial data infrastructure ( SDI) came to limelight in 1993, when it was first used by the United States national research council (US-NRC) to denote a framework that consists of institutional arrangements, policies and technologies that would create a conducive environment for the exchange of geographic information related resources in order to create a better information sharing community. SDI should enable creative innovation and delivery of spatial data held in data repositories through different channels of web services. Spatial data has different meanings and applications to users depending on their domain.

Researchers in the field of geospatial information have made tremendous advances in developing models for application in different geospatial communities especially in the developing countries; this has tended to mean it has received a global phase-lift. A second generation of spatial data infrastructures is now on board and a plan for a third is on the way. These are done with the hope of creating a spatially enabled society. Spatially enabled society accordingly, depicts a governance revolution where things are planned based on spatial information provided from a source-base repository, with citizens that are spatially informed so that the society would be better off for it $[38,35]$. It's worth mentioning here, that while some countries in the developing world are still dabbling with the problem of having to cope with developing a simple database using GIS and spatial infrastructure models developed by developed countries, the global spatial community is about, and moving into a third generation of SDI [29]. The aim of this study is to 
analyze the perception of GIS and SDI as perceived in most developing societies. This study looks at the term "developing societies", as countries that have not fully developed their capabilities in the field of geographic information system and spatial data infrastructure.

\section{The Problem}

Current trends in the field of geospatial information tend to shift attention from the production of highly automated spatial data to the compilation of spatial data geared towards coordinating and facilitating the exchange and sharing of spatial data between different users and producers of spatial information [35]. Almost all the developments and strides made in GIS and SDI study is in the developed countries of America, Europe, Canada and Australia. Other countries in the developing world are still lagging behind in confusion.

- Firstly, there is no clear cut difference between the terms used to describe GIS from that used in describing SDI.

- Secondly, the models currently being used for implementation in the developing countries are models meant for countries that have developed in their GIS and SDI capabilities.

- Thirdly, the facilities currently in some developing countries (especially Africa) may be likened to tending towards all-inclusive GIS and not infrastructure for GIS, that is, SDI.

There is therefore a problem of perception in these global developing communities as to the meaning and the difference between GIS and SDI, which prompted these kinds of questions to be asked. "I read the definition of both on Wikipedia but they didn't mention any relationship between the two terms, although there must be one because they are dealing with the same thing; spatial data. Can we consider that regional GISs are building blocks of a national SDI? "[20].In the view of this research, for an open geosource network to be achieved globally, these gaps must be filled.

\section{An Overview of GIS and SDI}

Many researchers have carried out work on GIS and SDI, especially in the area of SDI, which today has become a global phenomenon in the spatial information world. To the knowledge of this research, similar work has not been done in this area; however, studies that have direct bearing on this work would be discussed.

The concept of GIS which started in Canada about sixty years ago has seen systematic growth both in professionals and technical capabilities. The establishment of ESRI, an organization that has brought environmental scientists together to brainstorm on improved ways of producing geographic information data that could answer so many unsolved environmental questions is a good example. GIS has also seen tremendous growth in software, from the early day's software like Arc/INFO to the more modern versions of the Arc GIS. According to Jack Dangermond, pockets of individuals from different countries working independently brought about today's GIS. Thus, the questions about solving the problem of how to use, store, share and reuse volumes of data generated by the excesses of GIS has to be answered [17].

Globally, the concept of SDI started to be formulated in 1996 with the idea of having an international standard channel for sharing and or exchanging of spatial data from Global, Regional and National perspectives and vice-versa [9]. A motivational speech in 1998 by the then vice president of the United States, Al Gore, added impetus to the call for a global spatial information system, where the earth could be seen as a three dimensional-multi resolution planet, geo referenced for the visualization of social and physical information [12].The following sections discussed about related work of GIS and SDI around the world.

\subsection{Europe}

The thoughts of the developed countries are far away from thinking about GIS, though GIS and SDI can hardly be separated because of their peculiarities. Current trends have shown that their research is tailored towards SDI. Regional SDIs under the watchful eye of the Global Spatial Data infrastructures (GSDI), a global body for formulating; maintaining and monitoring of standards are being fortified. The European infrastructure for spatial information in Europe (INSPIRE) is a good example, it is a body responsible for the maintenance of standards for SDI in Europe. Though, they have not been able to achieve uniform standards because of the problem of transforming from current traditional delivery services to the more modern ICT based methods [1]. In spite of the interoperability problems, strides have been made in finding a road map with the inauguration of ATLAS of INSPIRE, aimed at mapping the challenges faced by implementing INSPIRE's SDI standards. Each government is being encouraged to produce an online portal in order to make geospatial plans available in digital format for public participation and input [37, 15]. Based on the observed trends in developed countries, fears have been expressed about the field of spatial data infrastructures developing and approaching a rapid critical point due to the anticipated maturity of research in the field of SDI, this is because at the moment, Europe and America seem to have satisfied the digital earth vision 2020 requirements [11]. SDI concept is also changing with time, with the idea of geo-sensors, presumably an act of collecting data when needed [5]. For the developed countries of America, Europe, Canada and Australia to mention but a few, it is the era of geospatial data towards e-government. In the Asia-Pacific region, countries like Australia, New Zealand, China, Japan, Korea to mention but a few are in the lead in the area of GIS and SDI.

\subsection{Asia-Pacific}


In Australia, the report on SDI has shown that advanced state has been reached not only in the provision of spatial data but also in the availability and access of spatial information from the pool of repositories provided. Some years back, this idea of e-participation in SDI at the community level due to the availability of internet technology was envisaged [40]. Quarterly report provided showed the number of searches made on a particular repository domain, search errors reported were as a result of poor metadata content. The report is given by Australian Spatial Data Directory (ASDD) an arm of Australian Spatial Data Infrastructure (ASDI) maintained by Geoscience Australia on behalf of ANZLIC, the spatial data infrastructure body for Australia and the New Zealand [36]. Australia and New Zealand occupy comfortable positions among the top ten developed countries of the world [25].

China, Japan and Korea are countries that have advanced in geographic information and spatial data infrastructures indicative of their advancement in electronic technology. In China, the official custodian of the geospatial data for the country is the National Geomatics Center of China (NGCC), under the supervision of the China National Spatial Data (CNSDI). The center is responsible for designing, maintaining, developing and updating of geospatial data for the national, provincial and municipal [8]. Such data are crucial in solving basic problems that are of national concern, such as environmental and land resources, threats to human life and natural disasters. In Japan, a prototype kind of approach to spatial information is adopted where a comparable application of spatial data models in other advanced SDIs is made, and a Japan- specific kind of models produced for implementation in different geospatial resource areas of the country's economy [30]. South Korea is a country that stands out with high potential to transform its self from an aid-dependent nation to a developed country; this is due to her capability in advanced IT technologies. Korea's SDI case study by the Information for Development (InforDev) was meant to assist developing countries to grow their SDI capabilities [24, 14].

The prospects for SDI are high for the developing countries of Malaysia and Indonesia as a result of a stable economy and stable system of accountability governance. In Malaysia, the task of coordinating geographic information (GI) and spatial data infrastructures is bestowed on the Malaysia Center for Geospatial Data Infrastructure (MACGDI) an arm of (MyGDI), the Malaysia Geospatial Data Infrastructure. A comparative study carried out on some developed SDIs and developing SDIs also showed the potential of Malaysia moving towards a spatially enabled society [23].

\subsection{Africa}

Africa's GI and SDI at the regional level is largely characterized by interventionist investments occasioned by external aids and, or individual countries' self-determination amidst a poor economy. In Africa, South Africa, Nigeria and
Egypt are seen as the countries in the lead in terms of available structure on the ground for GI and SDI knowledge acquisition, with countries like Algeria and Ethiopia following behind [10].

Africa is a continent in dire need of geographic information, with its vast natural resources, harsh climatic conditions in some areas, with hunger and starvation fuelled by inept and corrupt governance, the way forward should be for a sound SDI base for mitigation measures. The work of the Regional Centre for Mapping of Resources for Development (RCMRD) is highly applauded; it's the regional body for capacity building in surveying and mapping, geographic information systems, remote sensing and natural resources assessment and management. Aside this body that goes into partnership on behalf of member states with the development and donor agencies, individual countries are on their own [22].

South Africa seems to be the only country moving towards 'process' SDI, a geospatial community based concept whose focus is on creating a directory that links people, data and metadata together. The country also has a strong legislature on SDI with efforts being made to make spatial data access available with ease through the development of a national geospatial data clearinghouse. South Africa's Satellite Application Center Republic of South Africa (CSIR) is the only space agency in Africa listed as an observer on the Consultative Committee for Space Data Systems (CCSDS); a body whose cardinal focus is the standardization of common language for describing and expressing data so that there could be a uniform exchange of automated information among member agencies. South African universities stand out high among the highly rated universities in the world with the development of software like Ubuntu to show for this rating [3-34].

Successive governments in Nigeria have made attempts at having its Federal, State and Local government lands and land related facilities mapped, each state is saddled with the responsibility of mapping its own boundary and resources. In compliance with the federal government's directive each state ministry of land and survey has a GIS aimed at providing the teeming population with information about their land parcels. The spatial information provided is presumably supposed to be used for policy formulation, decision making economic planning and management. Nigeria's GIS and SDI quest is characterized by successes and failures. The National Space Research Development Agency (NASRDA) is the body established by law to coordinate the affairs of other bodies like the National Centre for Remote Sensing (NCRS), Regional Center for Training in Aerospace Surveys (RECTAS) and the Center for Space Science Technology Education (CSSTE) all charged with the task of training experts in GIS and remote sensing [33]. Aside from these organizations, higher institutions of learning are involved in the training of GIS professionals. Generally, GIS is fast establishing in the country, either in the form of standalone or concentrated. However, there is this lack of connectivity among these concerned bodies at 
state, regional and national levels $[33,32]$.

The pattern of production and distribution of maps in some Africa countries is done by map makers who may be on contract for the government. Quality and standards are maintained by these agencies that compete amongst themselves, producing map qualities based on characteristic domains. The increasing volume of these analogue maps, and the high agitation for a shift from shelf-based storage system to the electronic repository, has all brought to bear on GIS and SDI. It seems Africa is being rushed into accepting SDI at a time when most of the countries have not converted their maps from analogue to digital formats, indicating there is no firm grip on GIS yet. For example, according to Manisa and Nkwae [27], there is the need to clarify certain terms used to describe geospatial information such as, cadastres, geographic information system and spatial data infrastructure. Most of the assumptions forced down the throat of these countries by donor agencies do not seem to work, they are faulty models [7-29]. For instance it is estimated that the cost of having a standard clearinghouse is put at 1.5 million pounds (Crompvoets et al., 2004) which is almost a substantial part of the budget of some smaller countries. Africa's GIS/SDI should be tailored towards systematic development since development process is complex, and requires harnessing natural and human resources. SDI would only provide the desired service if it is sustained. To sum it all any planning for GI and SDI needs of developing countries should be geared towards an orderly transfer of knowledge from the project to the intended user community $[21,39]$.

\section{Methodology}

An overview of the systematic evolution and developments in GIS and SDI was itemized, with emphasis on the 'source' countries, that is, countries from where GIS and SDI first came to be known, texts and sources reviewed were those that had direct bearing to the study. Three regions were selected for the analyses. Europe, Asia-Pacific and Africa, this gives an even spread. In Europe, almost all the countries are well informed about the intention of INSPIRE and well aware of the importance of geospatial information for economic planning and sustainable growth. In Asia Pacific, it is a mixture of developed and developing capabilities for geographic information science and SDI. Some of the countries have reached the standards comparable to that of Europe and America.

Africa is a good case of, a developing geographic information science system, and SDI. A summary of the GIS and SDI position in the region was made, pointing out areas of concerns. A comparison of GIS and SDI level of readiness of some developed and developing countries were made to buttress the level of comprehension and preparedness for GIS and SDI.

\section{Results}

Results from the reviewed texts showed that GIS and SDI are well established in the developed countries of Europe, America and Asia-Pacific. It revealed an enhancement of long time research in the field of geospatial information systems, with some problems of data exchange being experienced as a result of interoperability problems. It also revealed an absolute energy capability of the countries involved, since electronic data exchange, the basis for a standard SDI, must be put in place for web services sharing and exchange of spatial information. A gap is also observed between the developed and developing countries in terms of system requirements, knowledge, technology, politics and policy requirements.

Developing countries showed a trend of undeveloped and or developing standards for SDI readiness. What seems to be the peculiar problem in most of the countries is how to develop their capability base in geographic information science (GIs) aimed at enhancing GIS capabilities; perhaps the issue of lack of political instability coupled with self-inflicted poverty and inadequate energy supply to power the economy may be some obvious reasons for these inadequacies.

\section{Discussion}

\subsection{Functionalities of GIS and SDI}

In the reviewed texts, there were no absolute terms that were used to describe or define a GIS that is quite different from those used for SDI. First and foremost, this study tries to look at the definition of the two from functionality angles, what does GIS do? What is SDI?

As already stated in the previous sections, so many definitions have been given to GIS. We now look at this one where it says, GIS consists of the hardware that is the components of the physical machine, the software, the professionals (experts) and information/data. Data collection is being stressed by this opinion as being critical to the success of GIS [28]. At this level one may see GIS as a system where raw or already processed geographic information is collected and processed or reprocessed by human experts on a machine installed with the machine language capability to produce geographic information/data which may still be used, stored, manipulated, analyzed and retrieved as the case may be. Thus the concept of GIS is that, it is a tool for the production of digital geographic information/data.

Over 100 countries around the world are actively involved in the construct of a national spatial data infrastructure (NSDI) [38], but what does spatial data infrastructure (SDI) entail? Some authors have said it is a framework, others a system; all however agree that it involves the sharing of geographic information or spatial data. SDIs make available the fuel for modern spatial analytical tools used in most GIS software [28]. The dynamics of spatial data infrastructure 
concept are composed of, the people, access network, policy, standards and information/data. Fig. 1 depicts the nature and relations between SDI components, known as the 'product' components [35]. Thus, for SDI to come into play to serve the need of the users and the stakeholders, the components mentioned above must be brought to bear.

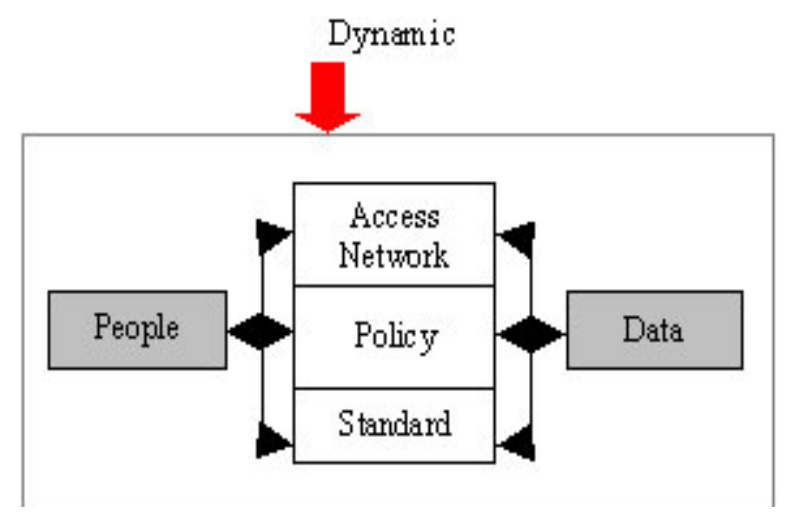

Figure 1. Nature and relations between SDI components [35].

\subsection{GIS and SDI Perception}

Let us assume that the standard model for effective GIS and SDI implementation is given by the component of SDI in Fig.1, with all the parameters of people, access network, technical standards, policy and data being met. We assume also that without these five parameters in place SDI implementation is not practically feasible.

We now look at 'people' as consisting of the users and suppliers of GIS and SDI and access network as the sum total technology for electronic transfer and sharing of spatial information from global, to regional, national, municipal and local levels and vice- versa. In the developed countries, whose capability for GI and SDI is high, the situation would seem to be normal, since the chance of development in new technologies and ideologies on SDI is higher and energy supply is also constant. Thus the standard requirement of $\mathrm{SDI}$ is met in this case.

In most developing countries, especially in Africa, energy supply is erratic, and a large number of the population relies on home-generators for power supply. In short, others are thinking of hunger and political crisis rather than generating electrical energy to power the economy. In this case our model diagram Fig. 1 would not fit into such countries, it would fit into Fig. 2 with access network absent due to lack of energy supply.

We now look at the parameter 'policy,' where policy can look to have a mild consequence, since mere policies based on politics can be formulated. It is very vital for the success of spatial data sharing and gives the guideline for achieving standard at both national and local levels in line with regional and global standards. Thus, if policy requirement is not satisfied, then our model in Fig. 1 is not satisfied, and so the model without policy would fit into Fig. 3.

Formulating policy on standards may be easy, but producing spatial data that would scale through international organization standardization (ISO) and open geospatial consortium (OGC), whose functions is to describe the exchange and transfer protocols between data servers may not be easy. Reports have shown that at the individual level, most developing countries lack standards in GI and SDI. It was also observed that some countries have not yet converted from analogue to digital format of map-making, in which case with standard absent such countries would fit into Fig. 4 [1]

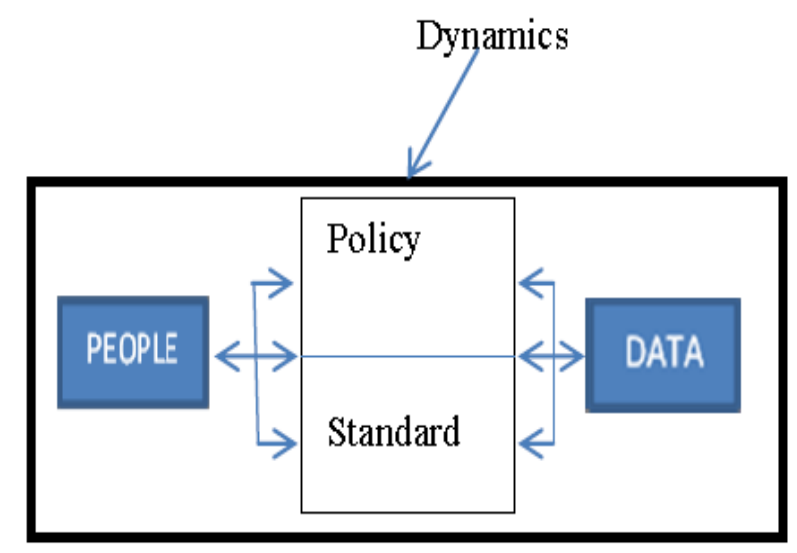

Figure 2. SDI components without access network [35].

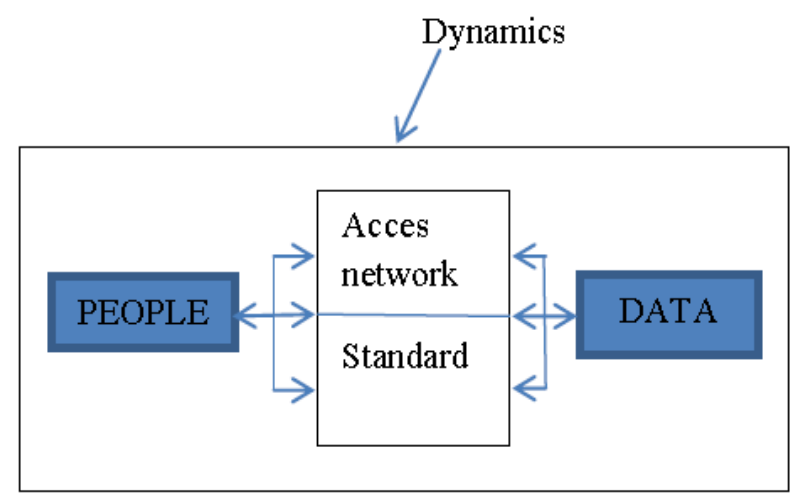

Figure 3. SDI components without policy [35].

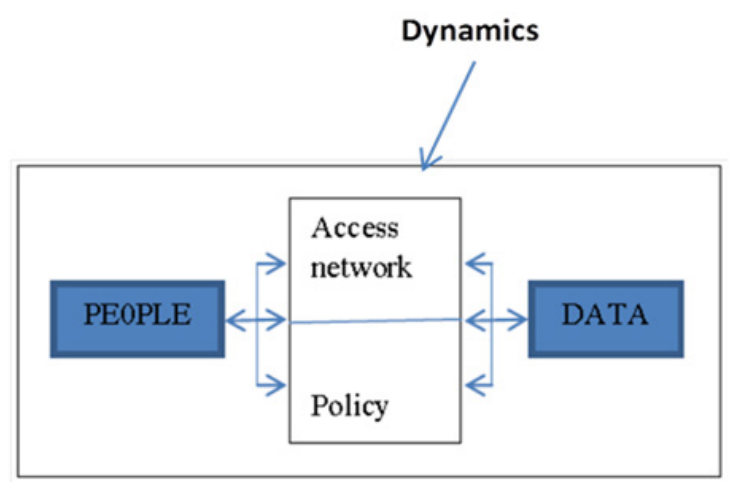

Figure 4. SDI components without standard [35].

Taking 'people' and 'data' from the extremes, this study thinks data at these levels are interchangeable, that is, information/data processed using GIS may still serve as raw data for reuse depending on the kind of information required, 
for example creating maps from maps. Thus, Fig. 1 satisfy international SDI standards mostly found in developed SDIs, which may be deemed to be the perception of GIS and SDI which works in unison to produce geospatial information in these developed countries.

\subsection{GIS and SDI Perception in Developing Societies}

From Figs 2-4, there exists the situation where each country in the developing societies has its specific and peculiar problems, either from access network, policy and technical standards added to the factor of finance, poverty and political instability coupled with lack of technical expertise, ignorance and, or awareness. The perception of GIS and SDI in the developing societies is vague. Others at the lower level of society see SDI as mere extension of GIS mentioned during government and non-governmental organization organized conferences. This is evidenced in the lack of geographic information science knowledge in most countries, where such facilities exist, they are not properly coordinated. SDI is seen in some societies as a mere subject introduced into the school curriculum meant for the academia alone.

\subsection{Suggested Model Perception}

These days, GIS and SDI are hardly distinguished because of the terms used in describing them, and the online capability of the GIS; however, an attempt is made here to give a clear difference between these terms. GIS as stated previously, consists of the hardware that is the components of the physical machine, the software, the professionals (experts) and information/data. A system where raw or already processed geographic information is collected and processed or reprocessed by human experts on a machine installed with the machine language capability to produce geographic information/data which may still be used, stored, manipulated, analyzed and retrieved as the case may be. Thus the concept of GIS is that, it is a tool for the production of digital geographic information/data.

SDI on the other hand involves the sum total of the technology, policy and standards to share available geospatial data across to various users and stakeholders for economic, political and management of informed decisions to enhance vital societal values. Thus the concept of SDI is that it is an electronic data repository and or clearinghouse used for the exchange and sharing of spatial information with specific standard requirements met through the use of web services.

Secondly, standard models produced for developing SDIs should be those ones that would take into consideration the peculiarity of each country before it is applied or implemented. For instance, InforDev partnership research in NSDI monitoring of development outcomes for each country should be done towards identifying the model that suits that country rather than having a standard model based on average few peculiar problems. As indicated in Figs 2-4 above each country lacks one of the basic components that form the requirement for implementing standard SDI. For example such research done in Uganda lamented the lack of standards, digital data sets availability, technology, manpower and other issues [19].

Thirdly, as a measure to achieve standard global SDI enhancement, countries should be given standard requirements in conformity with ISO and OGC standards to fulfill before they can be recognized under the GSDI regional body [31]. This would serve to encourage participating countries who only attend conferences just to answer 'present'. It is time for developing countries' GIS and SDI to move away from conferences to reality.

\section{Conclusion}

The study highlights on the perception of geographic information system (GIS) and spatial data infrastructure (SDI) in the developing societies, which are societies that have developed less in the area of geographic information science and spatial data infrastructure. Analysis of the developments and achievements of the early and present GIS and SDI was carried out based on reviewing texts obtained from web services and published texts. Three geospatial community regions were analyzed which revealed a gap between the developed and developing GIS and SDIs. These gaps were noticed in the area of the terminologies used in the description of GIS and SDI. Standard components of SDI were also found lacking in the areas of access network, policy and technical standards, the issue of available experts were played down. These gaps exist as a result of so many factors, prominent among which are the issues of faulty approach to geographic information science, coupled with SDI models that could not fit into developing societies' realistic needs. It also indicated that SDI is seen in most developing societies as an extension of GIS introduced into school curricula. A suggested model was developed for possible application in developing societies, which calls for studies in geographic information science as a step towards achieving an understanding of all inclusive GIS and SDI. Developing societies' models should be specific to the peculiar problem at hand, standards should also be monitored and serve as a requirement for recognition by the regional SDI under the GSDI regulations.

\section{REFERENCES}

[1] I. Abugessaisa, A. Ostman. Testing-SDI e-Government Perspective, Requirement and Challenges, International Journal of Public Information System, 1, 11-47, 2011.

[2] AD-SDI. Abu Dhabi Spatial Data Infrastructure, United Arab Emirate. Online available from http://sdi.abudhabi.ae/Sites/S $\mathrm{DI} /$ Navigation $/ \mathrm{EN} /$ faqs, did=80826, fragmentnr $=2 . \mathrm{html}$. 
[3] ANSWERSAFRICA. Top 10 Most Technologically Advanced Countries in Africa - Answers Africa. Online Available from

http://answersafrica.com/top-10-most-technologically-advan ced-countries-in-africa.html.

[4] B. W. Bishop, L. H. Mandel. Utilizing geographic information systems (GIS) in library research, International Journal of Geographic Information System, 28, 536-547, 2010.

[5] A. Bregt, J. Crompvoets, E. de Man, L. Grus. Challenges in Spatial Data Infrastructure research: a role for transdisciplinarity? GSDI 11 Spatial Data Infrastructure Convergence : Building SDI Bridges to address Global Challenges, Rotterdam, The Netherlands, 15- 19 June, 2009.

[6] CCSDS. The Data Description Language East Specification (CCSD0010), ccsds publication. Onlineavailable from http://public.ccsds.org/publications/archive/644x0b3.pdf.

[7] N. Chaminama. Analysis of Public Sector Cooperation and Geoinformation Sharing: A resource dependence perspective, Dissertation. International Institute for Geo_information Science and Earth Observation, Enschede, The Netherland, 2009.

[8] J. Chen, X. Chen. Development of National Spatial Data Infrastructure (NSDI) in China: Progress and Applications.,Journal of Geospatial Engineering The Hong Kong Institution of Engineering Surveyors 5 (2), 2003

[9] D. Clarke. Initiatives and Challenges of SDI in South Africa. Processing Technical: National Geo-spatial Information, South Africa. PositionIT_nov-dec11-Pro_33-35_2, 2011.

[10] S. Coetzee, S. Eksteen. Tertiary Education Institution in Africa: Cloudy with a Chance of GI SC Education in some Countries, South African Journal of Geomatics, 1 (2), 2012.

[11] M. Craglia, K. De Bie, D. Jackson, M. Pesaresi, G. Remetey-Fülöpp, C. Wang, A. Annoni, L. Bian, F. Campbell, M. Ehlers, J. Van Genderen, M. Goodchild, H. Guo, A. Lewis, R. Simpson, A. Skidmore, P. Woodgate. Digital Earth 2020: towards the vision for the next decade, International Journal of Digital Earth, 5, 4-21, 2012.

[12] M. Craglia, M. F. Goodchild, A. AnnonI, G. Camara, M. Gould, W. Kuhn, D. Mark, I. Masser, D. Maguir, S. Eliang, E. Parsons. Next-Generation Digital Earth* A position paper from the Vespucci Initiative for the Advancement of Geographic Information Science, International Journal of Spatial Data Infrastructures Research, 3, 146-167, 2008.

[13] J. Crompvoets, A. Bregt, A. Rajabifard, I. Williamson. Assessing the worldwide developments of national spatial data clearinghouses, International Journal of Geographical Information Science, 18, 665-689, 2004.

[14] A. C. Davis Jr., F. Fonseca. National Data Spatial Infrastructure: The Case of the Brasil. Washington, D.C. infodev/World Bank. Online available from http://www.infodev.org/publications.

[15] W. T. DE vries, J. Crompvoets, J. Stoter, I. Vandenberghe. Atlas of INSPIRE- Evaluating SDI Development through an Inventory of INSPIRE Experiences of European National Mapping Agencies. International Journal of Spatial Data Infrastructures Research, 6, 126-144, 2011.

[16] ESRI. What is a Geographic Information System (GIS).
Online available fromhttp://www.esri.com/what-is-gis/overv iew\#top_five_panel.

[17] EXAMINER.COM. Interview with Esri's Jack Dangermond Landscape Architecture and GIS History, National Landscape Architecture. Online available from http://www.examiner.co $\mathrm{m} /$ article/interview-with-esri-s-jack-dangermond-landscapearchitecture-and-gis-history.

[18] J. George. Efforts and Activities to make Data Accessible through Development of National Geospatial Data Clearinghouse in GSDI 12 Conference I Singapore Workshop PS 1.1c, 2010.

[19] GIC/ESRI. Feasibility Study for a National Spatial Data Infrastructure in Uganda, Washington, D.C.: infoDev / World Bank. Available from http://www.infodev.org/publications/.

[20] GIS.STACKEXCHANGE. How Geographic Information System and Spatial Data Infrastructure are Related. Online available from http://gis.stackexchange.com/questions/24871/how-gis-and-s di-spatial-data-infrastructure-are-related/.

[21] GLOVIA. Implementation Method: Simplified Implementation with Maximized Region of Interest. Onlineavailable from http://www.glovia.com/pdf/datasheets/ GloviaImplementationMethodology.pdf.

[22] GSDI. Spatial Data Infrastructure- Africa Newsletter, February_2013. The Geo-Spatial Community, 12 (2), 2013.

[23] M. O. Idrees, V. Saeidi, Y. A. Yusuf, A. R. M. Shariff. Comparing Approaches and Strategies for NSDI Implementation Between the Developed and Developing World, Article under Review for theInternational Journal of Spatial Data Infrastructures Research, 2012.

[24] E. H. Kim. National Spatial Data Infrastructure: The Case of Republic of Korea Washington, D. C: infoDev/World Bank. Online available from http://www.infodev.org/publications.

[25] LISTDOSE. Top 10 Most Developed Countries in the World. Online available from http://listdose.com/top-10-most-devel oped-countries-in-the-world/.

[26] H. Makumbi. Investigating the Influence of Resource Dependencies on Compliance to National Policies of Geo-information: A Resource Dependence Perspective. A case study of geo-information sector in Uganda, Dissertation. International Institute for Geo-information Science and Earth Observation, Enschede, The Netherland, 2010.

[27] M. Manisa, B. Nkwae. Developing Botswana Spatial Data Infrastructure: From Concept to Reality. FIG Working Week: Hong Kong SAR, China, 13-17 May 2007.

[28] J. Masó, X. Pons, A. Zabala. Tuning the second-generation SDI: theoretical aspects and real use cases. International Journal of Geographical Information Science, 26, 983-1014,2012.

[29] M. Musinguzi. A Tree Model for Diffusion of Spatial Data Infrastructures in Developing Countries. Online available from http://mak.ac.ug/documents/Makfiles/aet2011/Musinguzi_I.p df.

[30] M. Muto, T. Tsunoda, F. Kumasaka . Development of Marine Spatial Data Infrastructure in Japan. Online available from http://www.gsdi.org/gsdiconf/gsdi12/papers/86.pdf. 
[31] OGC. Open Geospatial Consortium: Geography Markup Language. Online available fromhttp://www.opengeospatial. org/standards/gml.

[32] O. A. Ogundele, G. I. Agbaje. Evaluation of Stakeholders Perception of Nigeria NGDI Using Technological Frame Theory. 1RegionalCentre for Training in Aerospace Surveys (RECTAS), Ile-Ife, Nigeria; 2National Space Research and Development Agency, Abuja, Nigeria, 2009.

[33] O. A. Ogundele, O. S. Somefun. SDI: Prospects and Challenges for Federal,States Developing Countries ( case of Nigeria) The International Archives of the Photogrammetry, Remote Sensing and Spatial Information Sciences. Vol. XXXVII. Part B4. Beijing 2008.

[34] QS. World University Rankings. Online available from http://www.topuniversities.com/university-rankings/world-u niversity-rankings/2012

[35] A. Rajabifard, I. P. Williamson . Spatial Data Infrastructures: Concept, SDI Hierarchy and Future Directions in Geomatics' 80 Conference, Tehran, Iran, 2001. .
[36] C. Tang, L. Lam. Benchmarking Spatial Data Infrastructure Development in Hong Kong in FIG Working Week: Bridging the Gap between Cultures Marrakech, Morocco, 18 - 22 May 2011

[37] D. Vandenbroucke, D. Biliouris. Spatial Data Infrastructures in The Netherlands : State of the Play EC-INSPIRE, Spring 2011, The Netherlands, 2011.

[38] I. Williamson, A. Rajabifard, J. Wallace, R. Bennett. Spatially Enabled Society in FIG Working Week: Bridging the gap between Cultures, Marrakech, Morocco, 18-22 May, 2011.

[39] D. O. F. Yawson, A. Armah, A. N. M. Pappoe. Enabling Sustainability: Hierarchical Need-Based Framework for Promoting Sustainable Data Infrastructure in Developing Countries. Sustainability 2009, 11, 946-959, 2009.

[40] T. Yigitcanlar. Australian Local Governments Practice and Prospects with Online Planning. URISA: Journal of The Urban and Regional Information Systems Association, 18, 7-17, 2006. 